\title{
Effect of Sulfation on Zirconia-Pillared Montmorillonite to the Catalytic Activity in Microwave-Assisted Citronellal Conversion
}

\author{
Is Fatimah, ${ }^{1}$ Dwiarso Rubiyanto, ${ }^{1}$ and Thorikul Huda ${ }^{2}$ \\ ${ }^{1}$ Chemistry Department, Islamic University of Indonesia, Kampus Terpadu UII, Jl. Kaliurang Km 14, Sleman, \\ Yogyakarta 55581, Indonesia \\ ${ }^{2}$ Professional Program of Chemical Analyst Department, Islamic University of Indonesia, Kampus Terpadu UII, \\ Jl. Kaliurang Km 14, Sleman, Yogyakarta 55581, Indonesia
}

Correspondence should be addressed to Is Fatimah; isfatimah@uii.ac.id

Received 17 February 2014; Revised 20 June 2014; Accepted 23 June 2014; Published 10 July 2014

Academic Editor: Deepak Kunzru

Copyright (C) 2014 Is Fatimah et al. This is an open access article distributed under the Creative Commons Attribution License, which permits unrestricted use, distribution, and reproduction in any medium, provided the original work is properly cited.

Preparation of sulfated zirconia-pillared montmorillonite was carried out in two steps; zirconia pillarization and sulfation to zirconia-pillared montmorillonite. The prepared materials were characterized by using X-ray diffraction (XRD), measurement of the specific surface area, total pore volume and pore size distribution by the $\mathrm{N}_{2}$ adsorption method, scanning electron microscopyenergy dispersive X-ray (SEM-EDX), and surface acidity determination by using pyridine adsorption-FTIR analysis. The activity of the materials as catalysts was evaluated for a microwave-assisted conversion of citronellal. The results showed that the prepared materials had a physicochemical character that promoted high catalytic activity to convert citronellal. From varied $\mathrm{Zr}$ content and study of the effect of sulfation on the activity, it was found that $\mathrm{Zr}$ content and sulfation increase the surface acidity of the material as shown by the higher total conversion and tendency to produce menthol as a product of the tandem cyclization-hydrogenation mechanism.

\section{Introduction}

Isopulegol is a very important intermediate in several chemical production processes including menthol production by the Takasago process. The cyclization reaction of citronellal to isopulegol is the main route in the conversion of some important flavors and chemical intermediates and for environmental reasons; some heterogeneous catalysts for the reaction have been studied. A number of heterogeneous catalysts have also been reported to be active in citronellal conversion such as zeolite beta, MCM-41, HY, mordenite, mixed oxides of $\mathrm{SiO}_{2}-\mathrm{TiO}_{2}, \mathrm{SiO}_{2}-\mathrm{ZrO}_{2}$, and $\mathrm{SiO}_{2}-\mathrm{Al}_{2} \mathrm{O}_{3}$ with and without copper, sulfated zirconia, and metal cation-exchanged montmorillonites [1] Among these materials, zirconia and sulfated zirconia have been receiving much attention due to their solid acidity and chemical stability as well as the thermal stability and superiority in hydrocarbon conversions such as in alkylation, cyclization, and isomerization [2-5].

A previous report showed that $\mathrm{S}-\mathrm{ZrO}_{2}$ catalyses the cyclisation of citronellal with high conversion and selectivity [6].
Considering the eco-friendly process, some investigations have considered either zirconia immobilized solid support or the use of zirconia as metal support. In case of immobilization, sulfation of zirconia can be performed to produce higher solid acidity in relevance with higher conversion in organic reaction mechanisms including cyclization. Referring to the physicochemical properties of montmorillonite mineral having a high specific surface area and porous structure, this research is aimed at combining the advantages of sulfation and immobilization. This work investigates the preparation, characterization, and catalyst activity of sulfated zirconiaimmobilized montmorillonite material. Based on the surface acidity and porous structure of the montmorillonite structure enhanced by pillarization and sulfation which are important characteristics of heterogeneous catalysis, the combined modification is hypothesized to significantly improve catalyst activity and selectivity as well as the reusable properties of the catalyst. Preparation is based the scheme of in situ preparation of sulfated zirconia and in situ sulfated zirconia clay 
$[4,7]$. The effect of the preparation method on physicochemical characteristics and also catalytic activity were evaluated.

\section{Materials and Method}

2.1. Materials. Citronellal, isopulegol and menthol, and zirconium isopropoxide were purchased from Sigma (USA). Montmorillonite was obtained from Boyolali, Jawa Tengah, and other chemicals such as anhydride acetic acid, nbutylamine, $\mathrm{n}$-hexane, and methanol for gas chromatography were of HPLC grade and obtained from Merck-Millipore (Germany).

2.2. Method. Sulfated zirconia montmorillonite was prepared in three steps: activation of montmorillonite, $\mathrm{ZrO}_{2}$ pillarization to obtain $\mathrm{ZrO}_{2}$-pillared montmorillonite ( $\left.\mathrm{Zr} / \mathrm{MMT}\right)$, and sulfation to $\mathrm{Zr} / \mathrm{MMT}$ to produce sulfated zirconiapillared montmorillonite (S-Zr/MMT). The activation process of montmorillonite was carried out by refluxing natural montmorillonite with sulfuric acid for $6 \mathrm{~h}$ followed by neutralization, drying, and grinding. The preparation of $\mathrm{Zr} / \mathrm{MMT}$ was performed in varied theoretic $\mathrm{Zr}$ content: $5 \%, 10 \%$, and $15 \%$ initialized by preparing $\mathrm{Zr}$ precursor from $\mathrm{ZrOCl}_{2} \cdot 8 \mathrm{H}_{2} \mathrm{O}$ solution combined with $\mathrm{Ba}(\mathrm{OH})_{2}$ at the mole ratio of $\mathrm{Zr}: \mathrm{Ba}=4: 1$. Activated montmorillonite was mixed with the precursor solution under constant stirring, followed by refluxing for $8 \mathrm{~h}$. After the reaction, the solid obtained by filtration was washed with distilled water until no chloride ions were detected with silver nitrate $\left(\mathrm{AgNO}_{3}\right)$; then it was dried at $120^{\circ} \mathrm{C}$ for $24 \mathrm{~h}$ before being calcined at $500^{\circ} \mathrm{C}$ for $4 \mathrm{~h}$. Zirconia-pillared montmorillonites obtained by this procedure are encoded as Zr/MMT-5, Zr/MMT-10, and $\mathrm{Zr} / \mathrm{MMT}-15$. The sulfation process of $\mathrm{Zr} / \mathrm{MMTs}$ was carried out by mixing Zr/MMTs and ammonium sulfate with a Zr: sulfate in a molar ratio of 1:6 followed by grinding in a carnelian mortar for $20 \mathrm{~min}$, aging, and calcination for $4 \mathrm{~h}$ at $400-800^{\circ} \mathrm{C}$ as in the previous method [4]. From overall steps, the samples produced are designated as $\mathrm{S}$ Zr/MMT-5, S-Zr/MMT-10, and S-Zr/MMT-15, respectively. For comparison purposes, sulfated zirconia was synthesized by the method described above.

2.3. Characterization. XRD analysis of materials was conducted by Ni-filtered $\mathrm{Cu} \mathrm{K} \alpha$ radiation $(\lambda=1.5406 \AA)$. The angle $(2 \theta)$ was measured in steps of $0.02^{\circ}$ between $5^{\circ}$ and $85^{\circ}$. The surface morphologies and also elemental analysis of the samples were evaluated by using the scanning electron microscopy-energy dispersive X-ray (SEM-EDX) method, and for the specific surface area investigation the catalyst samples were measured according to the Brunauer-EmmettTeller (BET) method with nitrogen adsorption at $77.4 \mathrm{~K}$ on an ASAP 1200 instrument (Micromeritics, USA) with the degassing conditions of $150^{\circ} \mathrm{C}$ for $2 \mathrm{~h}$. Surface acidity of solids are conducted by pyridine adsorption followed by FTIR measurements. Samples of Zr/MMTs and S-Zr/MMTs were placed in desiccators and were evacuated by vacuum pump for $1 \mathrm{~h}$ before pyridine vapor exposing for $4 \mathrm{~h}$. The samples were then reevacuated for $1 \mathrm{~h}$ before and were analyzed by
TABLE 1: Result of elemental analysis of materials.

\begin{tabular}{lccccc}
\hline \multirow{2}{*}{ Material } & \multicolumn{5}{c}{ Composition (\%wt.) } \\
& $\mathrm{Si}$ & $\mathrm{Al}_{2} \mathrm{O}_{3}$ & $\mathrm{Zr}$ & $\mathrm{Mg}$ & $\mathrm{Na}$ \\
\hline Zr/MMT-5 & 63.01 & 14.07 & 7.14 & 0.01 & 1.34 \\
Zr/MMT-10 & 66.41 & 23.81 & 10.7 & 0.01 & 0.89 \\
Zr/MMT-15 & 59.27 & 19.32 & 18.2 & 0.01 & 0.74 \\
S-Zr/MMT-5 & 47.77 & 17.43 & 9.76 & 0.02 & 1.03 \\
S-Zr/MMT-10 & 65.45 & 10.80 & 10.9 & 0.14 & 1.04 \\
S-Zr/MMT-15 & 58.83 & 14.87 & 19.11 & 0.02 & 0.09 \\
S-ZrO $_{2}$ & - & - & 87.42 & - & - \\
\hline
\end{tabular}

an AVATAR FTIR spectrophotometer. Total acidity of the samples was measured using a potentiometric method of titration with $\mathrm{n}$-butylamine. N-Butylamine solution $(0.1 \mathrm{~N}$; $0,5 \mathrm{~mL}$ ) was added to the dispersion of $0.2 \mathrm{~g} \mathrm{Zr} / \mathrm{MMTs}$ and $\mathrm{S}-\mathrm{Zr} / \mathrm{MMTs}$ samples in acetonitrile solvent. The mixtures were kept under stirring for $3 \mathrm{~h}$ and then the unadsorbed n-butylamine for each mixture was determined by potentiometric titration. The electrode potential of the solution during the titration was measured with Hanna PH210. The total acidity was calculated based on the amount of adsorbed n-butylamine for corresponding mixture.

2.4. Catalyst Activity. The catalytic activity of the prepared materials was initiated in citronellal cyclization. The reactions were performed using a microwave-assisted reaction as described in the procedure reported previously [8]. In each run, $10 \mathrm{mmol}$ citronellal, $1 \mathrm{mmol} \mathrm{K}_{2} \mathrm{CO}_{3}$, and $0.05 \mathrm{~g}$ catalyst were mixed and then subjected to microwave irradiation for 15 minutes. The final mixture was then analyzed by GCMS with an FID detector.

\section{Results and Discussion}

3.1. Material Characterization. The content of zirconium and other components in the prepared materials is presented in Table 1. It can be seen that the $\mathrm{Zr}$ content in the prepared materials is in accordance with varied $\mathrm{Zr}$ content in pillarization step in that higher theoretic $\mathrm{Zr}$ content produced a higher $\mathrm{Zr}$ percentage in the prepared material. The value of the $\mathrm{Zr}$ content was not fixed to the theoretical content in the preparation; for example, the percentages of $\mathrm{Zr}$ are 7.14, 10.7, and 18.2\% wt. for Zr/MMT-5, Zr/MMT-10, and $\mathrm{Zr} / \mathrm{MMT}-10$, respectively. The discrepancies in these values were caused by some weight loss of raw mineral during filtration, neutralization, and calcinations. After sulfation the Zr content for all materials increased, probably caused by some leaching of silica and alumina as shown by the reduced silica and alumina content in the materials.

Figure 1 shows the XRD pattern of $\mathrm{Zr}$ /MMTs prepared material compared to the raw material (activated montmorillonite). All reflections show the pattern of montmorillonite in the peaks at $6.3^{\circ}, 19.9^{\circ}$, and $35.5^{\circ}$ which correspondence to $d_{001}(14.9 \AA), d_{020}$, and $d_{006}$, respectively. After pillarization, the shift [001] reflection to the lower angle is shown from around 5.25 to $5.9^{\circ}$ indicating the increasing basal spacing 


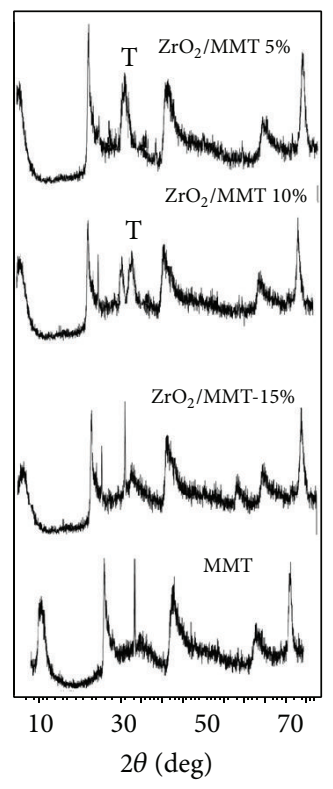

FIGURE 1: XRD pattern of $\mathrm{ZrO}_{2} / \mathrm{MMT}$.

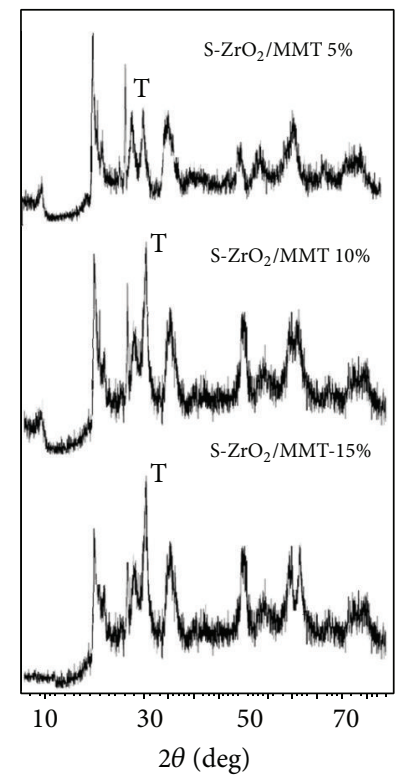

FIgURE 2: XRD pattern of S- $\mathrm{ZrO}_{2} / \mathrm{MMT}$.

$d_{001}$ as an effect of $\mathrm{ZrO}_{2}$ insertion in the interlayer space of the montmorillonite structure. The presence of dispersed zirconia is shown by some specific reflections observed at $30^{\circ}$ and $50^{\circ}$, corresponding to the [111] and [220] in that the formed phase is related to the calcination temperature at around $500^{\circ} \mathrm{C}$ coinciding with the phase change of the zirconiumhydroxy pillaring agent to the tetrahedral phase(T) as reported in similar works [9-11]. By the sulfation process (Figure 2), it can be seen that the reflection corresponding to $d_{001}$ of MMT disappeared, probably due to the impact of the acid environment, which destroyed the basal spacing, while
TABLE 2: Specific surface area, pore volume, and pore radius of materials.

\begin{tabular}{lccc}
\hline Sample & $\begin{array}{c}\text { Specific surface } \\
\text { area }\left(\mathrm{m}^{2} / \mathrm{g}\right)\end{array}$ & $\begin{array}{c}\text { Pore volume } \\
\left(\times 10^{-3} \mathrm{~cm}^{3} / \mathrm{g}\right)\end{array}$ & $\begin{array}{c}\text { Pore radius } \\
(\AA)\end{array}$ \\
\hline MMT & 89.55 & 0.230 & 8.7 \\
Zr/MMT-5 & 90.02 & 1.980 & 4.7 \\
Zr/MMT-10 & 97.50 & 1.940 & 8.2 \\
Zr/MMT-15 & 128.66 & 2.340 & 8.9 \\
\hline S-Zr/MMT-5 & 213.94 & 0.456 & 9.2 \\
S-Zr/MMT-10 & 265.45 & 0.389 & 8.9 \\
S-Zr/MMT-15 & 287.11 & 0.374 & 9.3 \\
S-ZrO & 225.08 & 0.786 & 9.8 \\
\hline
\end{tabular}

reflections associated with the presence of zirconia in the tetrahedral phase appeared.

The effects of zirconia dispersion on the surface profile presented as specific surface area, pore volume, and pore radius are listed in Table 2.

Zirconia-pillared montmorillonite and sulfated zirconiapillared montmorillonite showed higher specific surface area and pore volume compared to activated montmorillonite and pure synthesized- $\mathrm{ZrO}_{2}$ for all content of $\mathrm{Zr}$. Theoretically, the pillarization enhances the specific surface area parameter regarding the formation of metal oxide pillar between interlayer spaces of montmorillonite structure. It was also shown that the specific surface and pore volume increased with the increasing $\mathrm{Zr}$ content in that the formation of a porous structure from $\mathrm{Zr}$ precursor is probably related to the sol-gel mechanism during pillarization. However, the comparison between between MMT and Zr/MMt-5 is not significant. The relatively low content of zirconia is the reason for this data. The higher the zirconia content added in the pillarization procedure was, the more zirconia structure was formed in the composite. Furthermore, the pore volume data suggests the inconsistence in pore volume values in that the higher specific surface area gives the lower pore volume. This is the indication of the zirconia aggregation on the pores mouth so volume of the adsorbed gas was decreased. Compared to the $\mathrm{Zr} / \mathrm{MMT}$ samples, the S-Zr/MMT samples had higher specific surface area. The formation of a porous structure was revealed by the higher pore volume and external surface area indicating many accessible sites in the materials created by the sulfate interaction with surface zirconia particles that prevented zirconia aggregation as reported by [1]. The SEM profile depicted in Figure 3 shows examples of proof of the pore opening surface by the sulfation process to Zr/MMT-10 and Zr/MMT-5.

Effect of $\mathrm{Zr}$ in prepared materials on the total surface acidity and on surface acidity distribution was measured by pyridine-adsorption followed by FTIR analysis. Based on the acidity data in Table 2, a comparison between Zr/MMTs, $\mathrm{S}-\mathrm{Zr} / \mathrm{MMTs}$, and MMT showed that prepared materials exhibited higher total surface acidity and Lewis to Brönsted $(L / B)$ ratio compared to MMT. The higher the $\mathrm{Zr}$ content in the material, the higher the $L / B$ ratio. The ordering of $B / L$ and total acidity was consistent with the presence of Lewis acid 


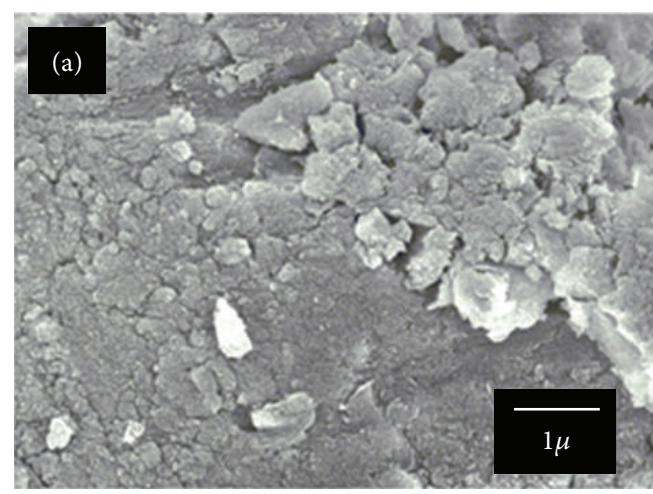

(a)

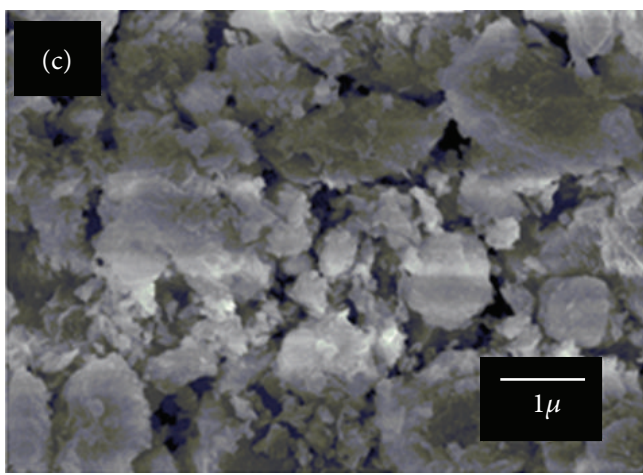

(c)

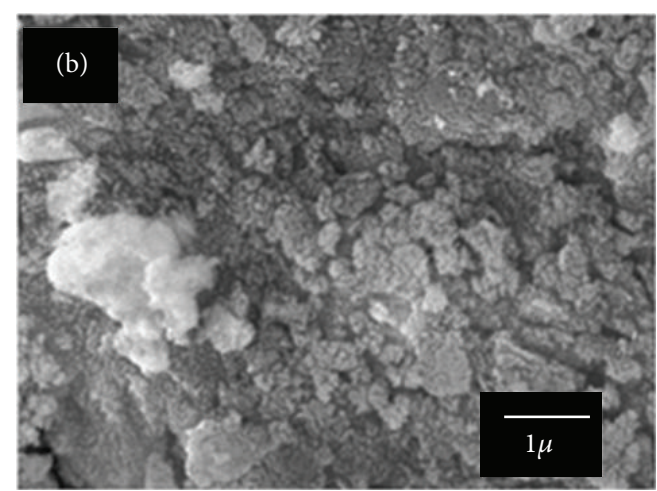

(b)

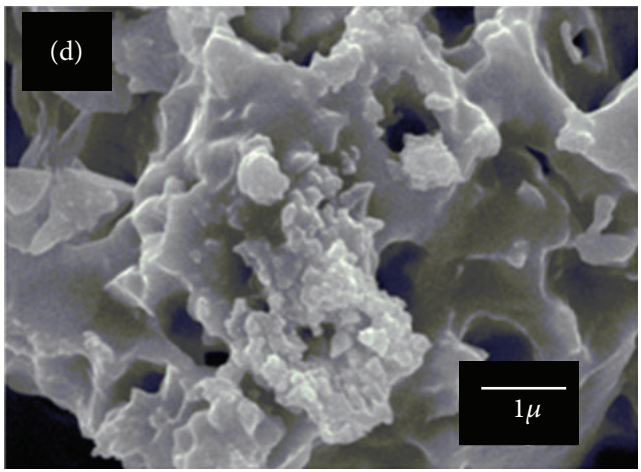

(d)

Figure 3: SEM profile of (a) Zr/MMT-5, (b) Zr/MMT-10, (c) S-Zr/MMT-5, and (d) S-Zr/MMT-10.

sites generated by dispersed $\mathrm{Zr}$ and sulfate ions. The result was in line with what was reported from the investigation on Zr dispersion in pillared montmorillonite [12].

Compared to raw material, Zr/MMTs have higher specific surface area and pore volume and the sulfation enhanced both parameters. The results were as expected as the main purpose of montmorillonite pillarization is to create a more specific surface area from the metal oxide pillars between silica-alumina sheets. From three varied zirconium contents it can be deduced that the higher the $\mathrm{Zr}$ content, the more porous the structure formed. Moreover, sulfation affected the specific surface area and pore volume in that after sulfation both parameters were enhanced. The pore opening was probably caused by the sulfation process due to the attachment of sulfate ions between the pores. The attachment of sulfate ions in the catalyst materials created more solid acid sites as shown by the total surface acidity data presented in Table 3.

The ratio of Brönsted acid to Lewis was calculated based on the ratio of intensity of the absorption at $1560 \mathrm{~cm}^{-1}$ with respect to the intensity of the absorption spectrum at $1450 \mathrm{~cm}^{-1}$ :

$$
\frac{B}{L}=\frac{I_{1540-1560 \mathrm{~cm}^{-1}}}{I_{1450-1455 \mathrm{~cm}^{-1}}}
$$

The FTIR spectra of materials after pyridine adsorption (Figure 4) showed that there were some absorption bands
TABLE 3: Total acidity and $B / L$ ratio of materials.

\begin{tabular}{lcc}
\hline Sample & $\begin{array}{c}\text { Total acidity } \\
\text { mmol of } \\
\text { n-butylammine/gram }\end{array}$ & $\begin{array}{c}\text { Brønsted/Lewis acid } \\
\text { ratio (FTIR) }\end{array}$ \\
\hline MMT & 0.775 & 0.85 \\
Zr/MMT-5 & 1.075 & 0.98 \\
Zr/MMT-10 & 1.09 & 1.06 \\
Zr/MMT-15 & 1.102 & 1.06 \\
S-Zr/MMT-5 & 1.120 & 1.12 \\
S-Zr/MMT-10 & 1.150 & 1.17 \\
S-Zr/MMT-15 & 1.150 & 1.22 \\
\hline
\end{tabular}

related to the presence of Lewis and Brönsted acid sites. From previous studies, four major absorption bands are 1623,1545 , 1490 , and $1445 \mathrm{~cm}^{-1}$, whereas the bands around $1545 \mathrm{~cm}^{-1}$ correspond to Brönsted acidity and $1445 \mathrm{~cm}^{-1}$ attributed to the Lewis acidity $[2,13,14]$. The band around $1445 \mathrm{~cm}^{-1}$ which resulted from the interaction between aromatic ring of pyridine and proton on surface was shown by all Zr/MMTs and S-Zr/MMTs samples from around 1436 to $1450 \mathrm{~cm}^{-1}$, while the band correlated with Brönsted acidity is expressed from the bands at around $1538-1550 \mathrm{~cm}^{-1}$. From Table 3 it can be concluded that total acidity was enhanced by the sulfation process. 

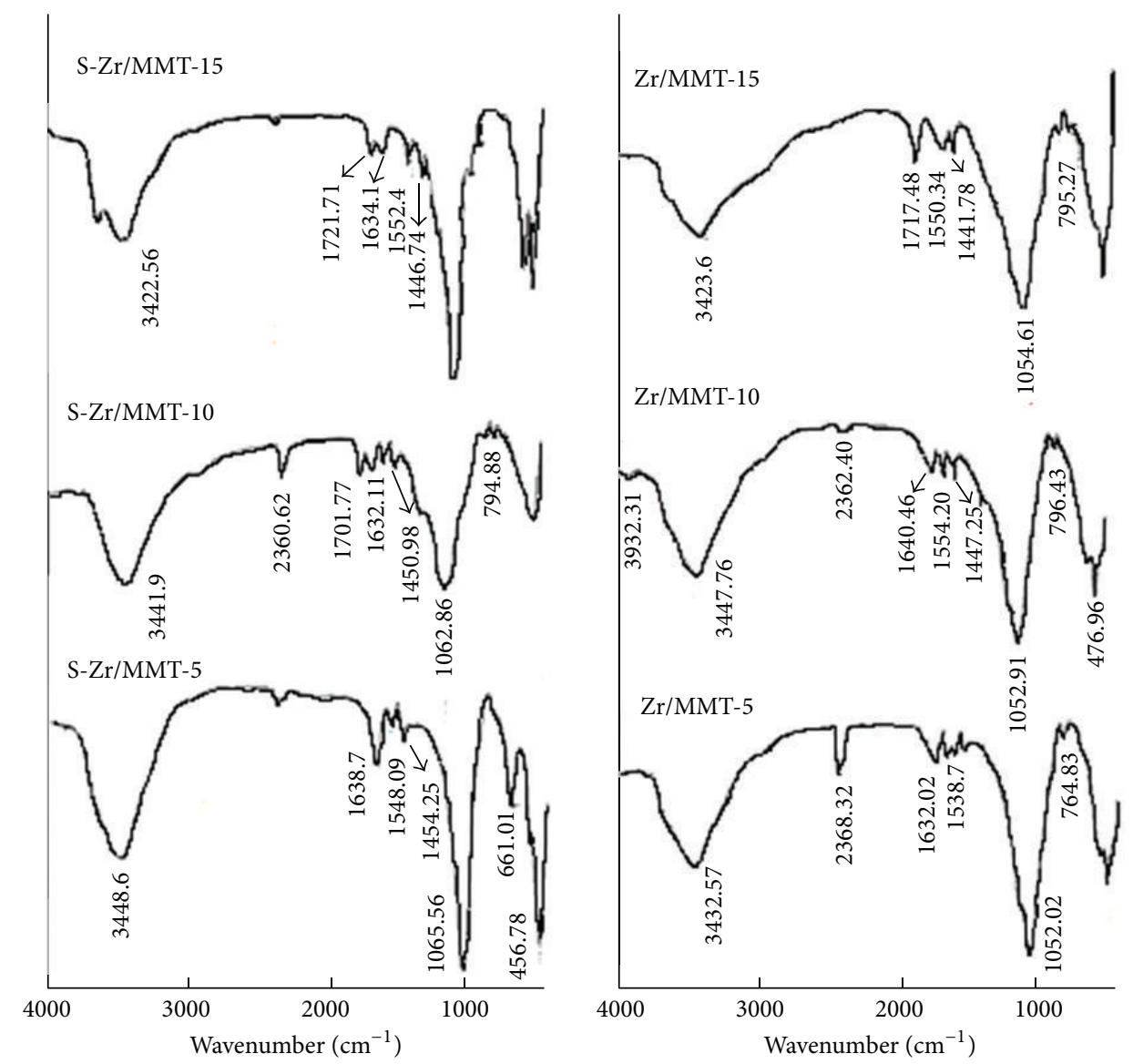

FIGURE 4: FTIR spectra of materials affect pyridine adsorption.

TABLE 4: Total conversion and selectivity on citronellal conversion over materials.

\begin{tabular}{lccc}
\hline \multirow{2}{*}{ Sample } & $\begin{array}{c}\text { Total } \\
\text { conversion }(\%)\end{array}$ & $\begin{array}{c}c \\
\text { Isopulegol } \\
(\% \mathrm{~mol})\end{array}$ & $\begin{array}{c}\text { Menthol } \\
(\% \mathrm{~mol})\end{array}$ \\
\hline MMT & 23.45 & 100 & - \\
Zr/MMT-5 & 68.76 & 98.6 & - \\
Zr/MMT-10 & 89.76 & 98.5 & - \\
Zr/MMT-15 & 79.22 & 100 & - \\
S-Zr/MMT-5 & 65.73 & 90.6 & 1.2 \\
S-Zr/MMT-10 & 90.54 & 98 & 2.0 \\
S-Zr/MMT-15 & 98.52 & 84.56 & 15.44 \\
S-ZrO 2 & 90.18 & 96 & 3.0 \\
\hline
\end{tabular}

3.2. Catalytic Activity. To study the effect of preparation especially sulfation and $\mathrm{Zr}$ content on the catalytic activity, each sample was tested in the microwave-assisted conversion of citronellal. Table 4 gives a summary of the total conversion and selectivity of isopulegol and menthol products based on the GCMS analyses. Total conversion and selectivity are determined based on a chromatogram of reaction result from the GCMS analysis:

Total conversion (\%)

$$
=\frac{[\text { Citronellal }]_{0}-[\text { Citronellal }]_{\text {product }}}{[\text { citronellal }]_{0}} \times 100
$$

$$
\text { Selectivity product }-i(\%)=\frac{[\text { product }]_{i}}{\sum_{i}^{n}[\text { Product }]} \times 100 \text {. }
$$

Here, [citronellal $]_{0}$ and [citronellal $]_{\text {product }}$ are the concentrations of citronellal in unreacted and in the product, [product] is the concentration of a specified product and $\sum_{i}^{n}$ [Product] is the total concentration of all products. The data are presented in Table 4.

In general, it can be concluded that S/Zr-MMTs samples give higher conversion compared to $\mathrm{Zr} / \mathrm{MMT}$ and MMT. For Zr/MMTs it can be seen that Zr/MMT-10 gives higher conversion compared to Zr/MMT-5 with the similar selectivity value, while $\mathrm{Zr} / \mathrm{MMT}-15$ exhibits lower conversion compared to Zr/MMT-10, but the selectivity of isopulegol product gained $100 \%$. The lower conversion may be related to the specific surface area and pore volume data of $\mathrm{Zr} / \mathrm{MMT}-15$, which are higher compared to Zr/MMT-5 and Zr/MMT-10. 
The higher specific surface area tends to adsorb the reactants strongly and hinders the adsorption-desorption mechanism of reactants and products. A similar reason may cause the lower conversion of the reaction over S-Zr/MMT-5 compared to $\mathrm{Zr} / \mathrm{MMT}-15$ samples. From the comparison of the total conversion data of S-Zr/MMT-5 and Zr/MMT-5, the sulfation process seems to have no effect on the catalytic activity since the conversion of reaction over S-Zr/MMT-5 is slightly lower than of Zr/MMT-5, while for the other S-Zr/MMTs the sulfation increases the total conversion remarkably. In contrast, with $\mathrm{Zr} / \mathrm{MMTs}$, from varied $\mathrm{Zr}$ content, the higher $\mathrm{Zr}$ content in S-Zr/MMTs gives higher total conversion. The synergistic effect of sulfate acid sites and zirconium atoms and the larger specific surface area within the catalyst probably causes the improvement of catalytic activity. A similar condition was reported by [15] for the positive effect of textural properties of catalyst and the catalytic activity. S-Z/MMT-15 catalyst showed considerable conversion of $98.52 \%$. It is also noted that menthol was produced by S-Zr/MMTs catalysts instead of isopulegol, while isopulegol is obtained by some solid acid catalysts by the following reaction equation:

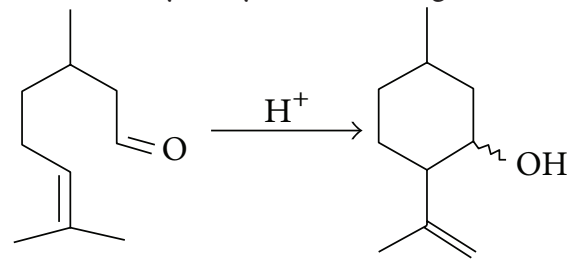

Even though in this work stereoisomer analysis of isopulegol was not carried out, it can be concluded that the higher content of acid sites in the catalyst provide the activity to citronellal to not only convert by isomerization or cyclization reaction but also by tandem cyclization-hydrogenation in a one pot system. A similar mechanism was reported in a previous investigation by using sulfated Pt-Ga/MCM-41 nanoparticles [8]. The highest selectivity to produce menthol was expressed by S-Zr/MMT-15 (15.44\%). The trend of total conversion and selectivity suggests that all physicochemical characteristics of catalysts are in line with the catalytic activity parameters. Sulfation and $\mathrm{Zr}$ pillarization bring the progress of solid to preserve catalytic active sites conduct the reaction which is in line with the aim of montmorillonite modification. Research works dealing with citronellal conversion have indicated that citronellal can be converted to isopulegol by catalysts containing exclusively Lewis or strong Brønsted acid sites with more selectivity using solids containing Brønsted/Lewis acidity [16-19].

\section{Conclusion}

Sulfated zirconia-pillared montmorillonites (S-Zr/MMT) have been synthesized from activated montmorillonites (MMT). The materials were characterized by XRD, $\mathrm{N}_{2}$ adsorption/desorption analysis, SEM, and surface acidity measurement. It was shown that the formation of the $\mathrm{ZrO}_{2}$ pillar with the enhancement of basal spacing $d_{001}$ of the montmorillonite structure was obtained and the character of zirconia was strengthened by the sulfation process. The total surface acidity and Brönsted to Lewis acid ratio show solid acidity enhancement by sulfation and pillarization to montmorillonite. These physicochemical characterizations demonstrated that the modification was successful in increasing catalytic activity. The highest activity was obtained by S$\mathrm{Zr} / \mathrm{MMT}-15$ with a total conversion of citronellal of $98.52 \%$.

\section{Conflict of Interests}

The authors declare that there is no conflict of interests regarding the publication of this paper.

\section{Acknowledgment}

Authors are grateful for the financial support of Unggulan PT DP2M DIKTI Contract No: 045/Dir/DPPM/70/Unggulan PT-DIKTI/V/2014.

\section{References}

[1] J. Rack Sohn, T. Kwon, and S. Kim, "Characterization of zirconium sulfate supported on zirconia and activity for acid catalysis," Bulletin of the Korean Chemical Society, vol. 22, no. 12, pp. 1309-1315, 2001.

[2] B. Tyagi, C. D. Chudasama, and R. V. Jasra, "Characterization of surface acidity of an acid montmorillonite activated with hydrothermal, ultrasonic and microwave techniques," Applied Clay Science, vol. 31, no. 1-2, pp. 16-28, 2006.

[3] B. Tyagi, M. K. Mishra, and R. V. Jasra, "Solvent free synthesis of acetyl salicylic acid over nano-crystalline sulfated zirconia solid acid catalyst," Journal of Molecular Catalysis A: Chemical, vol. 317, no. 1-2, pp. 41-45, 2010.

[4] S. Yu, P. Jiang, Y. Dong, P. Zhang, Y. Zhang, and W. Zhang, "Hydrothermal synthesis of nanosized sulfated zirconia as an efficient and reusable catalyst for esterification of acetic acid with n-butanol," Bulletin of the Korean Chemical Society, vol. 33, no. 2, pp. 524-528, 2012.

[5] A. Zali and A. Shokrolahi, "Nano-sulfated zirconia as an efficient, recyclable and environmentally benign catalyst for one-pot three component synthesis of amidoalkyl naphthols," Chinese Chemical Letters, vol. 23, no. 3, pp. 269-272, 2012.

[6] C. B. Cortés, V. T. Galván, S. S. Pedro, and T. V. García, "One pot synthesis of menthol from $( \pm)$-citronellal on nickel sulfated zirconia catalysts," Catalysis Today, vol. 172, pp. 21-26, 2011.

[7] S. Ben Chaabene, L. Bergaoui, A. Ghorbel, J. F. Lambert, and P. Grange, "In situ preparation of zirconium sulfate pillared clay: study of acidic properties," Applied Catalysis A: General, vol. 268, no. 1-2, pp. 25-31, 2004.

[8] A. M. Balu, J. M. Campelo, R. Luque, and A. A. Romero, "Onestep microwave-assisted asymmetric cyclisation/hydrogenation of citronellal to menthols using supported nanoparticles on mesoporous materials," Organic and Biomolecular Chemistry, vol. 8, no. 12, pp. 2845-2849, 2010.

[9] M. Bhagwat and V. Ramaswamy, "Synthesis of nanocrystalline zirconia by amorphous citrate route: structural and thermal (HTXRD) studies," Materials Research Bulletin, vol. 39, no. 11, pp. 1627-1640, 2004.

[10] G. K. Chuah, S. H. Liu, S. Jaenicke, and J. Li, "High surface area zirconia by digestion of zirconium propoxide at different $\mathrm{pH}$," Microporous and Mesoporous Materials, vol. 39, no. 1-2, pp. 381392, 2000. 
[11] N. Ahmad, S. T. Hussain, B. Muhammad, N. Ali, S. M. Abbas, and Z. Ali, "Zr-pillared montmorillonite supported cobalt nanoparticles for Fischer-Tropsch synthesis," Progress in Natural Science: Materials International, vol. 23, no. 4, pp. 374381, 2013.

[12] M. N. Timofeeva, V. N. Panchenko, A. Gil et al., "Effect of the acid-base properties of $\mathrm{Zr}$,Al-pillared clays on the catalytic performances in the reaction of propylene oxide with methanol," Applied Catalysis B Environmental, vol. 104, no. 1-2, pp. 54-63, 2011.

[13] M. P. Hart and D. R. Brown, "Surface acidities and catalytic activities of acid-activated clays," Journal of Molecular Catalysis A Chemical, vol. 212, no. 1-2, pp. 315-321, 2004.

[14] S. Mnasri and N. Frini-Srasra, "Evolution of Brönsted and Lewis acidity of single and mixed pillared bentonite," Infrared Physics and Technology, vol. 58, pp. 15-20, 2013.

[15] E. A. Emam, "Clays as catalysts in petroleum refining industry," ARPN Journal of Science and Technology, vol. 3, no. 4, pp. 356375, 2013.

[16] P. R. S. Braga, A. A. Costa, E. F. De Freitas et al., "Intramolecular cyclization of (+)-citronellal using supported 12-tungstophosphoric acid on MCM-41," Journal of Molecular Catalysis A: Chemical, vol. 358, pp. 99-105, 2012.

[17] C. B. Cortés, V. T. Galván, S. S. Pedro, and T. V. García, "One pot synthesis of menthol from ( \pm ) -citronellal on nickel sulfated zirconia catalysts," Catalysis Today, vol. 172, pp. 21-26, 2011.

[18] A. E. R. S. Khder, H. M. A. Hassan, and M. S. El-Shall, "Acid catalyzed organic transformations by heteropoly tungstophosphoric acid supported on MCM-41," Applied Catalysis A: General, vol. 411-412, pp. 77-86, 2012.

[19] M. Vandichel, F. Vermoortele, S. Cottenie, D. E. de Vos, M. Waroquier, and V. van Speybroeck, "Insight in the activity and diastereoselectivity of various Lewis acid catalysts for the citronellal cyclization," Journal of Catalysis, vol. 305, pp. 118-129, 2013. 

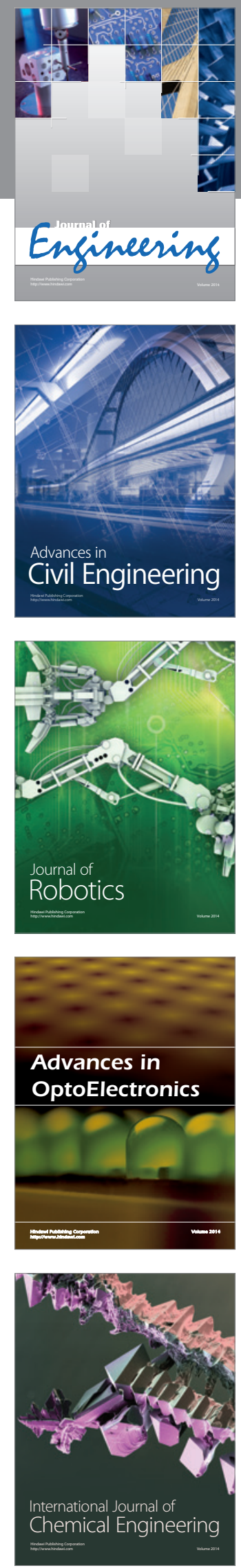

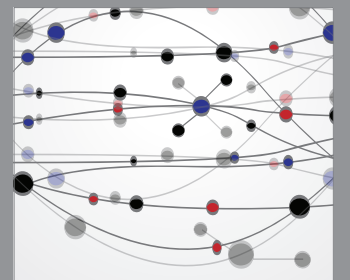

The Scientific World Journal
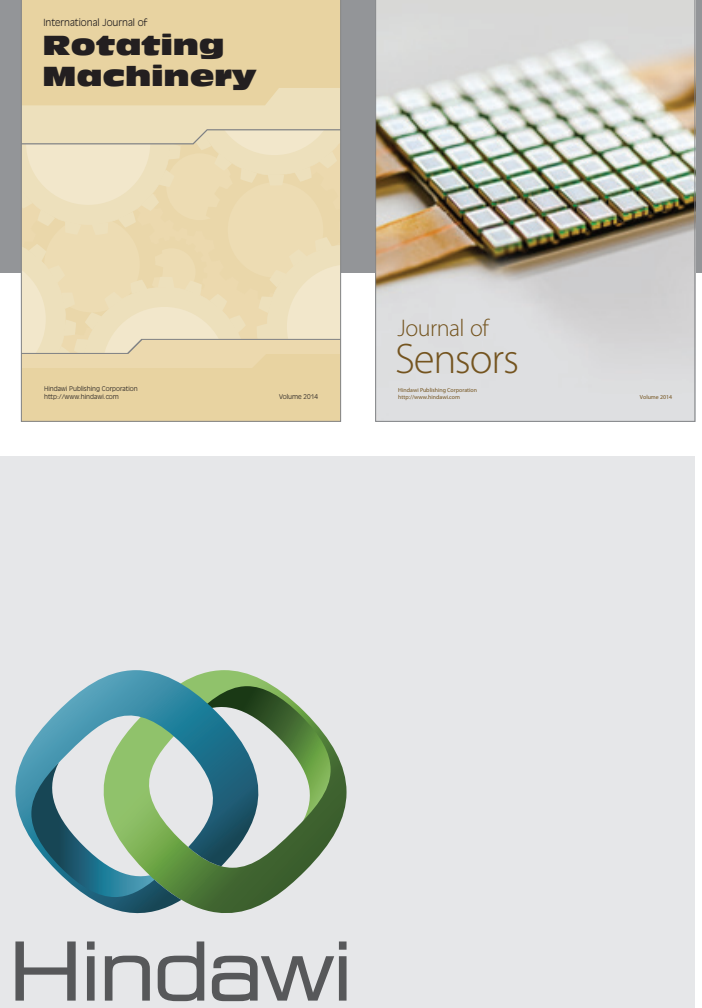

Submit your manuscripts at http://www.hindawi.com
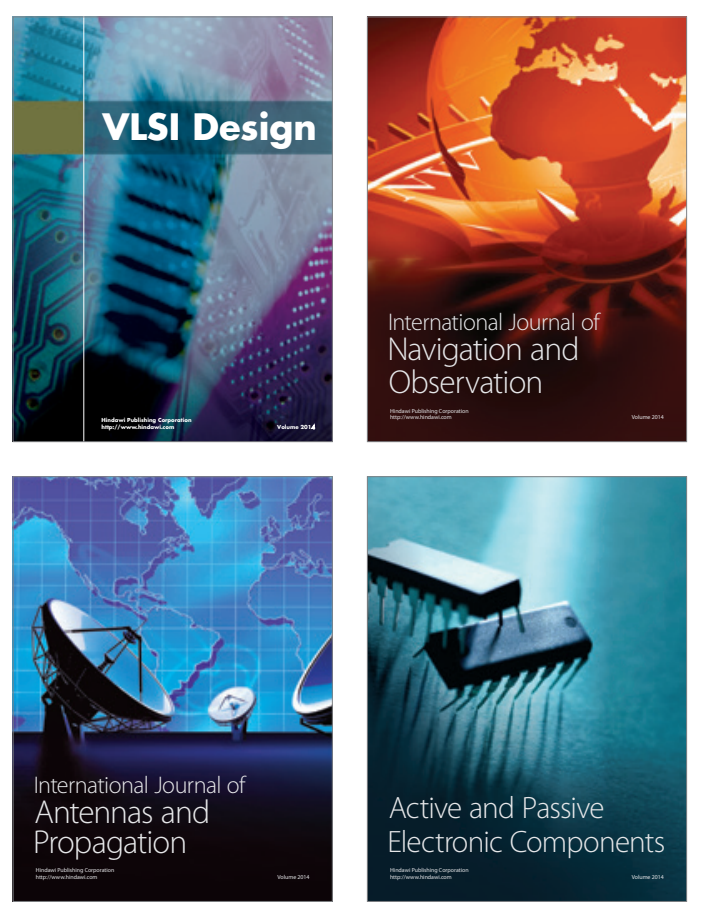
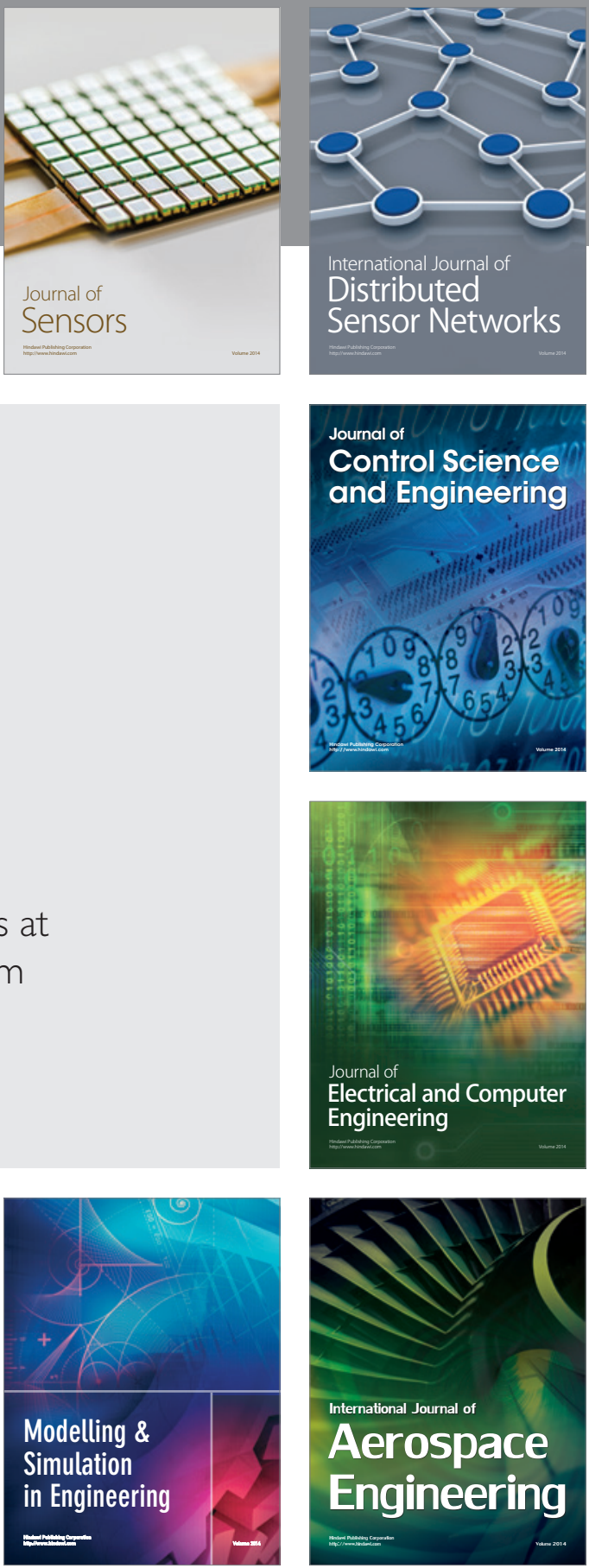

Journal of

Control Science

and Engineering
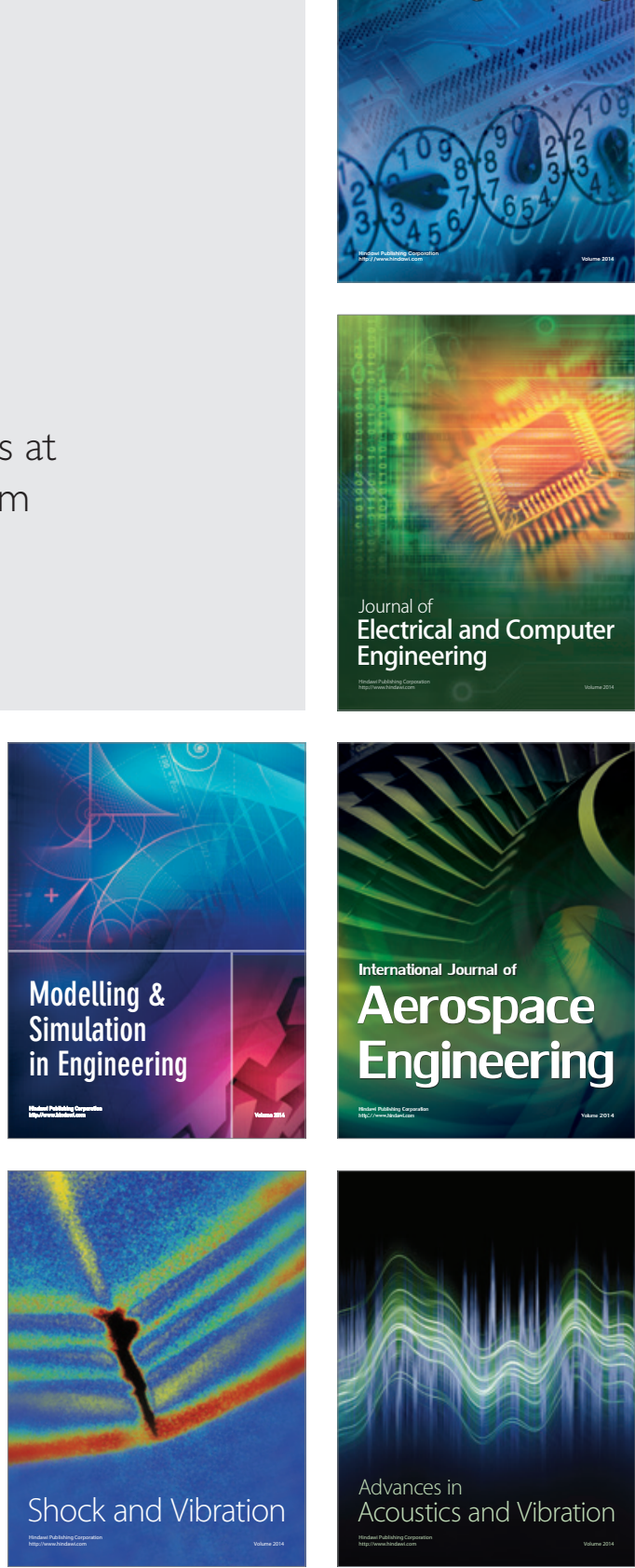